\title{
Extraction of indium(III) from chloride and nitrate media with 3-phenyl-4-benzoylisoxazol-5-one, HPBI, and tri-n-octylphosphine oxide
}

\author{
M. Chaoui Roqai, G.J. Goetz-Grandmont* and J.P. Brunette \\ Laboratoire de Chimie Analytique et Minérale de l'ECPM, UMR CNRS-ULP n7512, \\ 1 rue Blaise Pascal, BP. 296, 67008 Strasbourg, France
}

\begin{abstract}
The extraction processes of indium(III) from media of various complexing ability, chloride and nitrate, in toluene or chloroform, have been elucidated. Indium is extracted from $1 \mathrm{M}$ nitrate medium as $\mathrm{In}(\mathrm{PBI})_{3}$ with $\mathrm{HPBI}$ alone and as $\operatorname{In}(\mathrm{PBI})_{3}(\mathrm{TOPO})_{2}$ with TOPO-HPBI mixtures, while it is extracted from $1 \mathrm{M}$ chloride medium as $\operatorname{In}(\mathrm{PBI})_{3}$ and InCl $l_{x}(\mathrm{PBI})_{3-x}(\mathrm{TOPO})_{2}$. The complexation of In in the aqueous phases, the extraction of nitric acid and various solute-solute and solute-diluent interactions in the organic phases must be taken into account in the processes. The results are compared with those obtained previously with 1-phenyl-3-methyl-4-benzoyl-pyrazol-5-one under the same conditions.
\end{abstract}

Key words. Extraction - indium - acylisoxazolone - 3-phenyl-4-benzoyl-isoxazol-5-one - tri- $n$-octylphosphine oxide. 


\section{Introduction}

Since the first study of the liquid-liquid extraction of transition metal ions by Jyothi and Rao [1] with 3-phenyl-4-benzoylisoxazol-5-one, "HPBI", this chelating $\beta$-keto-enolic extractant has arisen a great interest $[2$ and reference therein, 3-9] because it allows the extraction of metal ions from rather acidic media, due to its high acidity $\left(\mathrm{pK}_{\mathrm{a}}=1.23\right.$ [10]). Compared to the well-known related heteroaromatic extractant 1-phenyl-3-methyl-4-benzoyl-5-hydroxypyrazole ("HPMBP", $\mathrm{pK}_{\mathrm{a}}=3.98$ [11]), the increase of the extraction constants ranges from one to seven orders of magnitude, depending of the extracted cation and of the experimental conditions. Moreover, the stereochemistry of the ligand in its chelated forms, i.e. in its metal complexes [12-14] and as a free ligand in the solid and in non-polar solvents [15], shows that it occupies a rather weak solid angle allowing the extraction of species with higher apparent coordination numbers than HPMBP, e.g. $\mathrm{Zn}(\mathrm{PBI})_{2}(\mathrm{TOPO})_{2}$ [2] or $\mathrm{Sr}(\mathrm{PBI})_{2}(\mathrm{TOPO})_{3}[3]$.<smiles>O=C(c1ccccc1)c1conc1-c1ccccc1</smiles>

HPB I

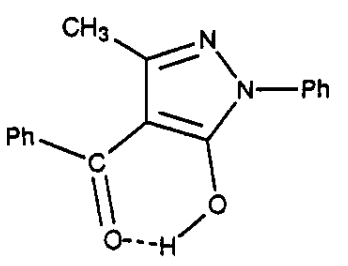

HPMBP
Fig. 1. The acidic extractants (tautomeric form in non-polar solvents).

This work consists in studies of indium(III) extraction, from concentrated chloride medium, with HPBI alone and its mixtures with the electron-donor synergist tri- $n$ octylphosphine oxide "TOPO", mainly in toluene. It is compared with its extraction from poorly complexing nitrate or perchlorate media [16, this work] and with our previous work upon its extraction from the same media with acylpyrazolones and synergists $[17,18]$.

\section{Experimental}

\section{Reagents}

Inorganics were Prolabo or Merck analytical grade products. Diluents were purchased from Prolabo ("Rectapur" quality), washed and pre-equilibrated with a blank (without $\mathrm{In}^{\mathrm{III}}$ ) solution before use. For syntheses, all the reagents were laboratory grade, purchased from Fluka, Aldrich or Prolabo.

The preparation of HPBI has been detailed in a previous paper [3]. HPMBP has been prepared by a known procedure [19]. Tri- $n$-octylphosphine oxide, "TOPO”, (Merck purum) was purified by washing of its chloroformic solution with aqueous carbonate and recrystallization.

\section{Nomenclature:}

HL: any monoacidic extractant. HX: any inorganic acid.

[F]: aqueous concentration of a species $\mathrm{F}$, after equilibration of the phases. The index "org" denotes a concentration in organic phase; " $i$ " denotes an initial concentration before contacting the phases.

$[\mathrm{In}]_{\mathrm{t}},[\mathrm{In}]_{\text {org }},[\mathrm{L}],[\mathrm{L}]_{\text {org }}$ : analytical concentrations of indium or chelatant.

$K_{\mathrm{d}}(\mathrm{F})=[\mathrm{F}]_{\text {org }} /[\mathrm{F}]$ : distribution constant of the species "F" between a given diluent and the aqueous phase. $D=[\mathrm{In}]_{\mathrm{org}} /$ $[\mathrm{In}]_{\mathrm{t}}$ : distribution coefficient of indium. $\mathrm{pH}_{1 / 2}=\mathrm{pH}$ corresponding to half-extraction $(D=1)$.

All the constants are conditional. The curves in the figures are guides for the eye.

\section{Extraction and analytical procedures}

Typical initial compositions of the phases were as follows. Aqueous phases: $[\mathrm{In}]_{i} \sim 2.17 \times 10^{-3} \mathrm{M},\left[(\mathrm{Na}, \mathrm{H}) \mathrm{NO}_{3}\right]$ or $[(\mathrm{Na}, \mathrm{H}) \mathrm{Cl}]=1 \mathrm{M}$; Organic phase: $[\mathrm{HL}]_{\mathrm{org}, i}=0.02 \mathrm{M}$, $[\mathrm{TOPO}]_{\mathrm{org}, i}=0.02 \mathrm{M}$, in chloroform and toluene.

The distribution measurements were performed using a batch technique in thermostatted vessels $\left(25.0 \pm 0.2^{\circ} \mathrm{C}\right)$. Equal volumes of both phases were contacted under magnetic stirring until the equilibrium was attained (max. $20 \mathrm{~min}$ ) and then separated by gravity. The $\mathrm{pH}$ was adjusted by $0.1 \mathrm{M} \mathrm{NaOH}+0.9 \mathrm{M} \mathrm{NaNO}_{3}$ (respectively $\mathrm{NaCl}$ ) aqueous solutions. For each experimental point, aliquots of both phases were withdrawn and the metal was stripped from the organic aliquot with $3 \mathrm{M} \mathrm{HNO}_{3}$. Metal concentrations were determined after suitable dilution by flame atomic absorption using a 2380 Perkin Elmer AA spectrophotometer.

\section{Results}

\section{Properties of the aqueous media}

Within the $\mathrm{pH}$ range of this study, the hydrolysis of indium is negligible. However, its complexation with $\mathrm{Cl}^{-}$and $\mathrm{NO}_{3}^{-}$ ions must be considered. It is characterised by the cumulative formation constants $\beta_{i}$ and the aqueous distribution ratios $\alpha_{i}$ :

$$
[\operatorname{In}]_{\mathrm{t}}=\Sigma\left[\operatorname{InX}_{i}^{(3-i)+}\right]=\left[\operatorname{In}^{3+}\right]\left(1+\sum \beta_{i}\left[\mathrm{X}^{-}\right]^{i}\right)
$$

with $\beta_{i}=\left[\operatorname{InX} X_{i}^{(3-i)+}\right] /\left(\left[\operatorname{In}^{3+}\right]\left[\mathrm{X}^{-}\right]^{i}\right)$

and $\alpha_{i}=\left[\operatorname{InX} X_{i}^{(3-i)+}\right] /[\operatorname{In}]_{\mathrm{t}}=\alpha_{0} \beta_{i}\left[\mathrm{X}^{-}\right]^{i}$.

The sets of $\beta_{i}\left(\mathrm{Cl}^{-}\right)$and $\beta_{i}^{\prime}\left(\mathrm{NO}_{3}{ }^{-}\right)$constants used are those of Ferri et al. [20] corrected for $1 \mathrm{M}$ ionic strength according to Aguilar et al. [21], and Ferguson et al. [22] respectively. They are reported in the tables I and II.

Table I. Complexation of indium in $1 \mathrm{M}$ chloride medium.

\begin{tabular}{ccccc}
\hline$i$ & 0 & 1 & 2 & 3 \\
\hline $\log \beta_{i}$ & - & 2.41 & 3.59 & 3.95 \\
$\alpha_{i}$ & $7.66 \times 10^{-5}$ & $1.97 \times 10^{-2}$ & 0.298 & 0.682 \\
$\log \alpha_{i}$ & -4.1158 & -1.7055 & -0.5258 & -0.1662 \\
\hline
\end{tabular}


Table II. Complexation of indium in $1 \mathrm{M}$ nitrate medium.

\begin{tabular}{cccc}
\hline$i$ & 0 & 1 & 2 \\
\hline $\log \beta_{i}^{\prime}$ & - & 0.1761 & 0.3098 \\
$\alpha_{i}^{\prime}$ & 0.334 & 0.502 & 0.164 \\
$\log \alpha_{i}^{\prime}$ & -0.4557 & -0.2996 & -0.7855 \\
\hline
\end{tabular}

\section{Properties of the extractants and their mixtures in biphasic media}

\section{HPBI}

The behaviour of acidic extractants is described by their acidity constant in aqueous phase $K_{\mathrm{a}}$, and for a given diluent, by their partition constant $K_{\mathrm{d}}$ and their biphasic acidity constant $K_{\mathrm{A}}$ :

$K_{\mathrm{a}}=\left[\mathrm{H}^{+}\right]\left[\mathrm{L}^{-}\right][\mathrm{HL}]^{-1}$ and $K_{\mathrm{A}}=[\mathrm{HL}]_{\mathrm{org}}^{-1}\left[\mathrm{~L}^{-}\right]\left[\mathrm{H}^{+}\right]$,

hence: $\mathrm{p} K_{\mathrm{A}}=\mathrm{p} K_{\mathrm{a}}+\log K_{\mathrm{d}}$.

From the data reported in table III and the above equations, the concentrations of HPBI in various media and that of $\mathrm{PBI}^{-}$in aqueous medium have been calculated for various pH's. It is shown that [HPBI] is negligible, compared with $[\mathrm{HPBI}]_{\text {org }}$ within the whole $\mathrm{pH}$ range, although $\left[\mathrm{PBI}^{-}\right]$ is negligible only for the lowest values of $\mathrm{pH}: \mathrm{pH}<\mathrm{p} K_{\mathrm{a}}$.

Table III. Properties of HPBI in liquid-liquid systems.

\begin{tabular}{lccc}
\hline & Toluene & Chloroform & 1,2-Dichloroethane \\
\hline $\mathrm{pK}_{\mathrm{a}}$ & $1.23^{*}[10]$ & 1.23 & 1.23 \\
$\log _{\mathrm{d}}$ & 2.29 & 3.02 & 2.86 \\
$\mathrm{pK}_{\mathrm{A}}$ & $3.52[2]$ & $4.25[24]$ & $4.09[23]$ \\
\hline
\end{tabular}

* determined in $0.1 \mathrm{M}(\mathrm{Na}, \mathrm{H})^{+} \mathrm{ClO}_{4}^{-}$.

\section{TOPO}

Extraction of inorganic acids: TOPO is known to be poorly soluble in aqueous phase and to extract some inorganic acids, e.g. $\mathrm{HClO}_{4}$ [25], $\mathrm{HNO}_{3}$ [26]. For this latter one, a 1:1 complex is extracted according to:

$\mathrm{H}^{+}+\mathrm{X}^{-}+\mathrm{TOPO}_{\text {org }}=(\text { TOPO.HX })_{\text {org }}\left(\right.$ constant $\left.K_{\mathrm{p}}\right)$.

The constants $K_{\mathrm{p}}$ are determined by measuring the $\mathrm{pH}$ variation of an aqueous phase, used for the quantitative stripping of HX, previously extracted with TOPO (see the Appendix 1).

Table IV. Extraction of inorganic acids with TOPO.

\begin{tabular}{lcc}
\hline $\log K_{p}{ }^{*}$ & Toluene & Chloroform \\
\hline $\mathrm{HCl}$ & $0.05 \pm 0.03$ & $-0.40 \pm 0.05$ \\
$\mathrm{HNO}_{3}$ & $0.72 \pm 0.04$ & $0.18 \pm 0.04$ \\
\hline
\end{tabular}

${ }^{*} \log K_{\mathrm{p}}$ values for $1 \mathrm{M}(\mathrm{Na}, \mathrm{H}) \mathrm{X}$ media.
As expected, the high hydration of chloride ions leads to a negligible extraction of $\mathrm{HCl}$, while on the contrary the extraction of $\mathrm{HNO}_{3}$ must be taken into account, especially in toluene.

TOPO - HL interactions: TOPO is also able to interact with acidic hydrogen atoms by H-bond formation. Using spectroscopic methods, evidence was given of such interactions in toluene, the more acidic HPBI leading to a stronger alteration of the $\mathrm{P}=\mathrm{O}$ bond than HPMBP. Moreover, in chloroform which also interacts with TOPO, minor alterations are shown with stoichiometric amounts of HPBI, while the effect of HPMBP is negligible [15]. The interaction constants in toluene have recently been investigated by liquidliquid methods in $(\mathrm{Na}, \mathrm{H}) \mathrm{NO}_{3} 1 \mathrm{M}$ medium:

$\mathrm{HPBI}_{\text {org }}+\mathrm{TOPO}_{\text {org }}=(\mathrm{TOPO} \cdot \mathrm{HPBI})_{\text {org }}\left(\right.$ constant: $\left.K_{\text {int }}\right)$.

Table V. Interaction of TOPO and acidic extractants in toluene.

\begin{tabular}{lllll}
\hline & HPBI & \multicolumn{2}{c}{ HPMBP } \\
\hline $\log K_{\text {int }}$ & $1.85 \pm 0.07$ & {$[3]$} & $0.85 \pm 0.07$ & {$[2]$} \\
\hline
\end{tabular}

\section{Extraction of Indium with HPBI alone}

\section{Extraction in toluene from chloride medium:}

Some representative extraction curves of indium from chloride medium in toluene, $\log D$ vs. $\mathrm{pH}$ are reported in figure 2 . They are approximatively linear with mean slopes 2.05 (0.01 M HPBI) to 2.81 (0.06 M HPBI). From these data, curves $\log D$ vs. $\log [\mathrm{HPBI}]_{i, \text { org }}$, at constant $\mathrm{pH}$, have been drawn and show slopes near 3 .

Hence, the following extraction equilibrium is assumed: $\mathrm{In}^{3+}+3 \mathrm{HPBI}_{\text {org }}=\operatorname{In}(\mathrm{PBI})_{3, \text { org }}+3 \mathrm{H}^{+}$(constant: $\left.K_{13}\right)$.
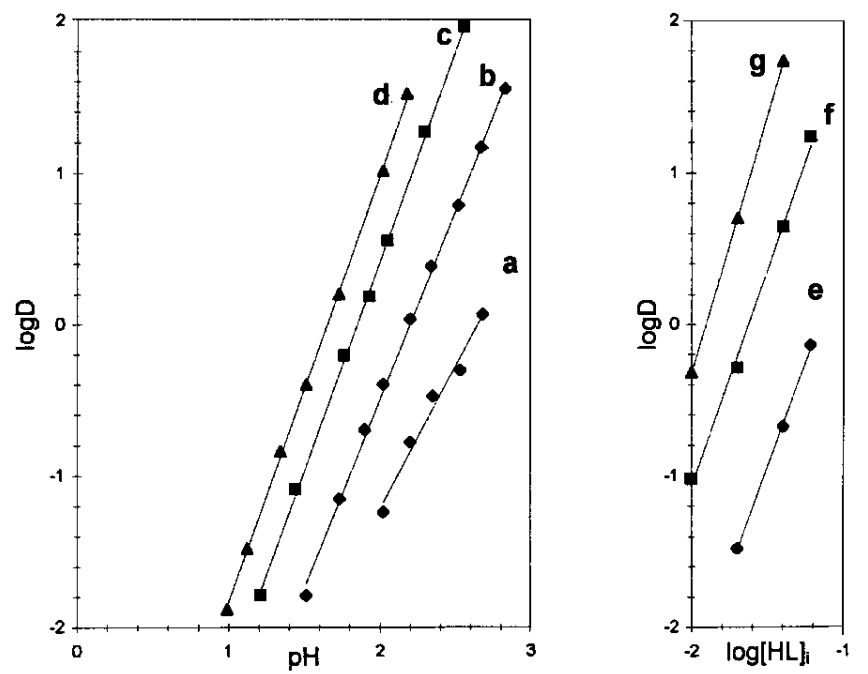

Fig. 2. Indium(III) extraction from chloride medium with HPBI in toluene. $(\mathrm{Na}, \mathrm{H})^{+} \mathrm{Cl}^{-}=1 \mathrm{M} ;[\mathrm{In}]_{i}=2.17 \times 10^{-3} \mathrm{M} ; 25^{\circ} \mathrm{C}$. $[\mathrm{HPBI}]_{\text {org }, i}$ $=0.01 \mathrm{M}(\mathrm{a}), 0.02 \mathrm{M}(\mathrm{b}), 0.04 \mathrm{M}(\mathrm{c}), 0.06 \mathrm{M}$ (d). $\mathrm{pH}=1.6(\mathrm{e})$, $2.08(\mathrm{f}), 2.48(\mathrm{~g})$. 
The rather low slopes of the curves $\log D$ vs. $\mathrm{pH}$ are attributed to the decrease of the organic concentration of free HPBI by complexation upon indium and by dissolving and dissociation in the aqueous phase.

With the above assumption, the mass balance of HPBI is:

$$
\begin{aligned}
{[\mathrm{HPBI}]_{\text {org }, i}=} & {[\mathrm{HPBI}]_{\text {org }}+3\left[\operatorname{In}(\mathrm{PBI})_{3}\right]_{\text {org }}+[\mathrm{HPBI}] } \\
& +\left[\mathrm{PBI}^{-}\right]+\sum j\left[\operatorname{In}(\mathrm{PBI})_{j}^{(3-j)+}\right]
\end{aligned}
$$

(Note that this equation is valid only because $V_{\text {aq }}=V_{\text {org }}$ ).

Assuming that the aqueous concentrations of HPBI and of $\operatorname{In}(\mathrm{PBI})_{j}^{(3-j)+}$ complexes are negligible:

$$
[\mathrm{HPBI}]_{\mathrm{org}}=\left([\mathrm{HPBI}]_{\mathrm{org}, i}-3[\mathrm{In}]_{\mathrm{org}}\right)\left(1+K_{\mathrm{A}} /\left[\mathrm{H}^{+}\right]\right)^{-1} \text {. }
$$

The values of $\log K_{13}$ have been calculated for every experimental point according to:

$\log K_{13}=\log D-3 \mathrm{pH}-3 \log [\mathrm{HPBI}]_{\text {org }}-\log \alpha_{0}$

$\log K_{13}($ tol, $\mathrm{Cl})=2.92 \pm 0.05$, from 23 experimental points.

The $K_{13}$ values show random fluctuations, i.e. they do not vary with $\mathrm{pH}$ or with $[\mathrm{HPBI}]_{\mathrm{org}, i}$, which would occur if another extraction equilibrium was part of the extraction process. Thus, the results are not consistent with the extraction of a mixed $\mathrm{InCl}_{n} \mathrm{~L}_{3-n}$ species.

\section{Extraction in toluene from nitrate medium:}

The extraction of indium from the poorly complexing nitrate medium (1 M) has been investigated for comparison. The extraction curves (Fig. 3) are analogous, except that the extraction from the nitrate medium is better than for the chloride one $\left(\mathrm{pH}_{1 / 2}\right.$ for $[\mathrm{HPBI}]_{i}=0.02 \mathrm{M}$ : 2.17 for $1 \mathrm{M} \mathrm{Cl}^{-}$, 0.88 for $1 \mathrm{M} \mathrm{NO}_{3}^{-}$). This is mainly due to the higher concentration of the extractible $\operatorname{~In}^{3+}$ species in nitrate medium than in chloride medium, for identical analytical indium concentrations. $\log K_{13}$ has been calculated as above, taking into account the $\beta_{i}^{\prime}$ aqueous complexation constants of indium with nitrate: $\log K_{13}\left(\right.$ tol, $\left.\mathrm{NO}_{3}^{-}\right)=2.90 \pm 0.06$, from 24 experimental points. Note that $\mathrm{In}^{\mathrm{III}}$ is extracted with HPBI in benzene, from $0.2 \mathrm{M}$ nitrate solution, according to the same equilibrium (3), with $\log K_{13}\left(\mathrm{bz}, \mathrm{NO}_{3}^{-}\right)=2.68$ [16], which is compatible with the above results.

\section{Influence of the diluent:}

The influence of the diluent upon the extraction efficiency is shown in figure 4, quantitative data are reported in table VI. They show that chloroform is a poor diluent compared with both toluene and dichloroethane.
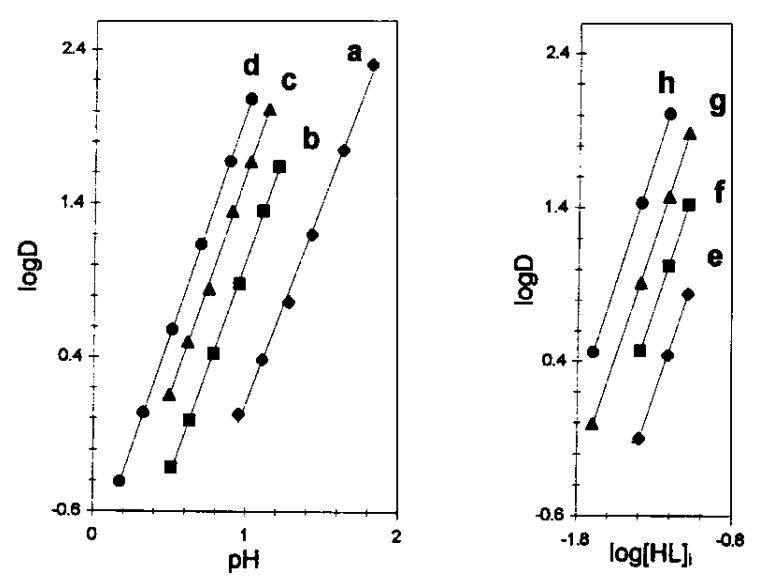

Fig. 3. Indium(III) extraction from nitrate medium with HPBI in toluene. $(\mathrm{Na}, \mathrm{H})^{+} \mathrm{NO}_{3}^{-}=1 \mathrm{M} ;[\mathrm{In}]_{i}=2.17 \times 10^{-3} \mathrm{M} ; 25{ }^{\circ} \mathrm{C}$. $[\mathrm{HPBI}]_{\mathrm{org}, i}=0.02 \mathrm{M}$ (a), $0.04 \mathrm{M}$ (b), $0.06 \mathrm{M}$ (c), $0.08 \mathrm{M}$ (d). $\mathrm{pH}=0.60$ (e), 0.80 (f), $0.95(\mathrm{~g}), 1.14(\mathrm{~h})$.

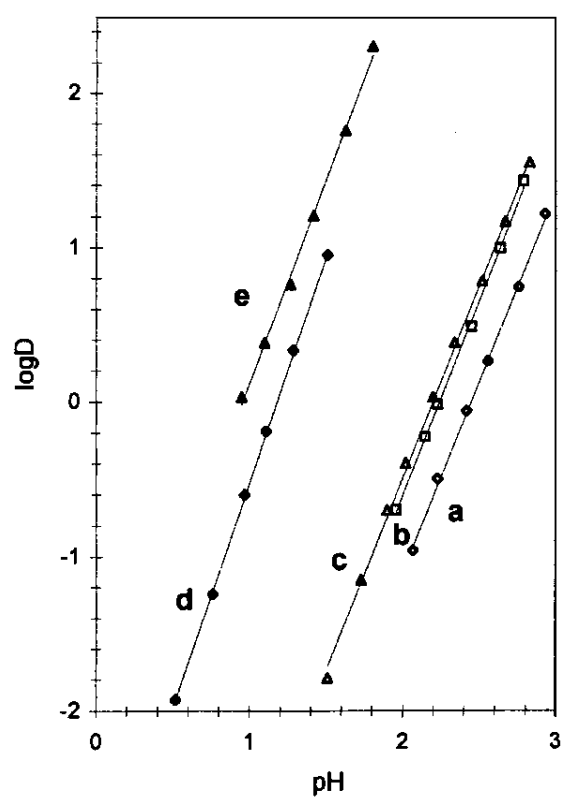

Fig. 4. Influence of diluents and aqueous media on the extraction of Indium(III) with $0.02 \mathrm{M}$ HPBI in toluene. $[\mathrm{In}]_{i}=2.17 \times 10^{-3} \mathrm{M}$; $25^{\circ} \mathrm{C} .1 \mathrm{M}(\mathrm{Na}, \mathrm{H})^{+} \mathrm{Cl}^{-}$: chloroform (a), 1, 2-dichloroethane (b),

\begin{tabular}{|c|c|c|c|c|c|}
\hline \multirow[t]{2}{*}{ DILUENT } & \multirow[t]{2}{*}{$\log K_{\mathrm{d}}(\mathrm{HL})$} & \multicolumn{2}{|c|}{$\mathrm{NO}_{3}^{-} 1 \mathrm{M}$} & \multicolumn{2}{|c|}{$\mathrm{Cl}^{-} 1 \mathrm{M}$} \\
\hline & & $\log K_{13}$ & $A^{*}$ & $\log K_{13}$ & $A^{*}$ \\
\hline toluene & 2.29 & $2.90 \pm 0.06$ & 13.46 & $2.92 \pm 0.05$ & 13.48 \\
\hline 1, 2-dichloroethane & 2.86 & & & $2.70 \pm 0.07$ & 14.97 \\
\hline chloroform & 3.02 & $2.29 \pm 0.06$ & 15.04 & $2.12 \pm 0.05$ & 14.87 \\
\hline
\end{tabular}
toluene (c). $1 \mathrm{M}(\mathrm{Na}, \mathrm{H})^{+} \mathrm{NO}_{3}^{-}$: chloroform (d), toluene (e).

Table VI. Diluent effect on the extraction of indium with HPBI.

${ }^{*} A=\log K_{13}+3 \mathrm{pK}_{\mathrm{A}}$. 
Considering the general relation upon the extraction of In $^{3+}$ with acidic extractants [27]:

$\log K_{13}=\log \beta\left(\mathrm{InL}_{3}\right)+3 \log K_{\mathrm{a}}(\mathrm{HL})-3 \log K_{\mathrm{d}}(\mathrm{HL})+$ $\log K_{\mathrm{d}}\left(\mathrm{InL}_{3}\right)$

where $\beta\left(\mathrm{InL}_{3}\right)=\left[\mathrm{InL}_{3}\right]\left[\mathrm{In}^{3+}\right]^{-1}\left[\mathrm{~L}^{-}\right]^{-3}$ is the overall formation constant of $\mathrm{InL}_{3}$ in the aqueous phase, let us define a parameter $A$ :

$$
\begin{aligned}
A & =\log K_{13}-3 \log K_{\mathrm{a}}(\mathrm{HL})+3 \log K_{\mathrm{d}}(\mathrm{HL}) \\
& =\log \beta\left(\operatorname{InL}_{3}\right)+\log K_{\mathrm{d}}\left(\operatorname{InL}_{3}\right) .
\end{aligned}
$$

Since $\log K_{\mathrm{a}}(\mathrm{HL})$ and $\beta\left(\mathrm{InL}_{3}\right)$ do not depend on the nature of the diluent, $\log K_{\mathrm{d}}\left(\mathrm{InL}_{3}\right)$ varies like $\mathrm{A}$ with the nature of the diluent. Therefore, for any pair of diluents:

$$
\begin{aligned}
\Delta \log K_{13} & =\Delta \log K_{\mathrm{d}}\left(\mathrm{InL}_{3}\right)-3 \Delta \log K_{\mathrm{d}}(\mathrm{HL}) \\
& =\Delta A-3 \Delta \log K_{\mathrm{d}}(\mathrm{HL}) .
\end{aligned}
$$

In all cases, the distribution constants of both complex and ligand are higher for the chlorinated diluents than for toluene. Since the extractions are less efficient in the former ones, the higher distribution of $\mathrm{InL}_{3}$ in 1, 2-dichloroethane or chloroform cannot compensate the lower aqueous concentration of HPBI in these systems, due to the higher $K_{\mathrm{d}}(\mathrm{HL})$ that induces a lower concentration of $\mathrm{PBI}^{-}$, which limits the formation of the extractable $\operatorname{In}(\mathrm{PBI})_{3}$ complex.

It is noticeable that the distribution constants of the $\mathrm{In}(\mathrm{PBI})_{3}$ complex in chloroform and 1, 2-dichloroethane are almost similar. The distribution constants of HL are significantly (if not much) different: $\Delta \log K_{\mathrm{d}}(\mathrm{HL})=0.16$. Since $\log K_{\mathrm{d}}(\mathrm{HL})$ contributes to $\log K_{13}$ with a -3 coefficient, this difference is enough to explain the noticeably lower extraction in chloroform than in dichloroethane. The high distribution constant of HPBI in chloroform might be attributed to its extra-solubilization due to intermolecular H-bond formation with the diluent.

Note that a lower extraction with $\beta$-keto-enols in chloroform than in aromatic diluents is often observed [26].

\section{Synergistic extraction of Indium with HPBI + TOPO}

\section{Extraction in toluene from nitrate medium:}

The extraction experiments in toluene are described in the figures $5 \mathrm{a}$ and $5 \mathrm{~b}$. From this aqueous medium, the extraction with TOPO alone is negligible, the extraction with HPBI is reported in figure 5a (curve a), showing a medium synergistic effect of TOPO. The $\log D$ vs. $\mathrm{pH}$ curves show slopes $\approx 3$ at highest $\mathrm{pH}$ 's, which agrees with the extraction of $\operatorname{In}(\mathrm{PBI})_{3}(\mathrm{TOPO})_{\mathrm{s}}$ species, according to the equilibria $(4, s)$ :

$\mathrm{In}^{3+}+3 \mathrm{HPBI}_{\text {org }}+s \mathrm{TOPO}_{\text {org }}=\operatorname{In}(\mathrm{PBI})_{3}(\mathrm{TOPO})_{\mathrm{s}, \text { org }}+3 \mathrm{H}^{+}$

$$
\text { (constant: } K_{13 \mathrm{~s}} \text { ). }
$$

At lowest pH's, the slopes increase dramatically, due to the extraction of protons as TOPO- $\mathrm{HNO}_{3}$ species. Within the whole $\mathrm{pH}$ range, the increase of the distribution coefficient of indium induced by regularly increasing the initial concentrations of TOPO or HPBI is not constant, since the formation of TOPO.HPBI decreases significantly the availability of free HPBI and free TOPO at high initial concentrations of the extractants. The three equilibria (1), (2) and $(4, s)$, with $s=1$ or 2 , have been taken into account to cal- culate the extraction constants $K_{131}(s=1)$ and $K_{132}(s=2)$ for each experimental point. A significant and regular variation of the values of $K_{131}$ is observed when varying each experimental parameter, $\mathrm{pH},[\mathrm{HPBI}]_{i, \text { org }}$ or $[\mathrm{TOPO}]_{i, \text { org }}$, which proves that the equilibrium $(4, s=1)$ alone cannot
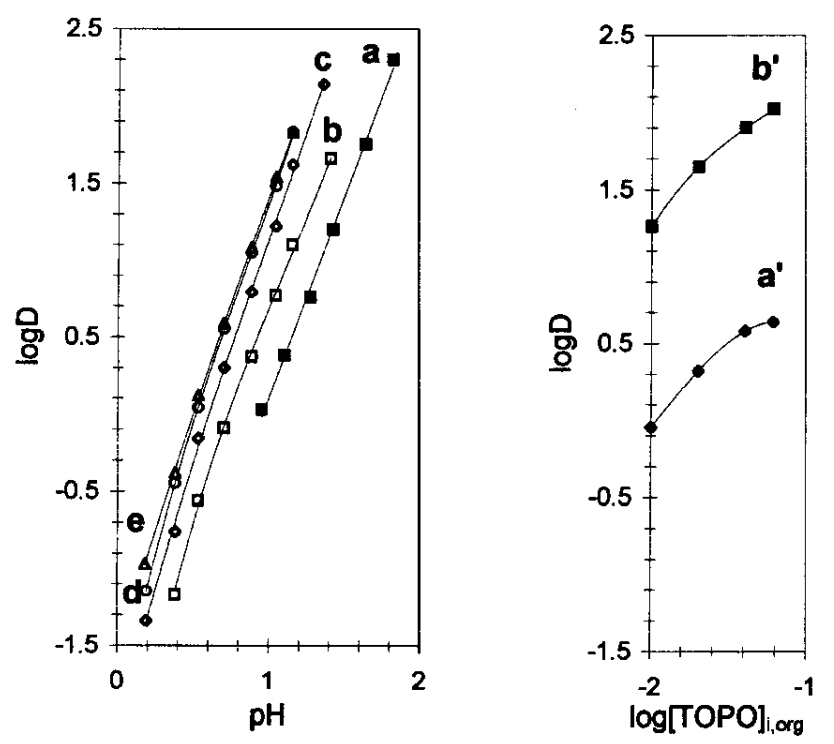

Fig. 5a. Indium(III) extraction from nitrate medium with HPBI + TOPO in toluene: influence of the electron-donor concentration. $(\mathrm{Na}, \mathrm{H})^{+} \mathrm{NO}_{3}^{-}=1 \mathrm{M} ;[\mathrm{In}]_{i}=2.17 \times 10^{-3} \mathrm{M} ; 25{ }^{\circ} \mathrm{C} ;[\mathrm{HPBI}]_{\mathrm{org}, i}=$ $0.02 \mathrm{M}$. [TOPO] $]_{\text {org }, i}=0.00 \mathrm{M}(\mathrm{a}), 0.01 \mathrm{M}(\mathrm{b}), 0.02 \mathrm{M}(\mathrm{c}), 0.04 \mathrm{M}$ (d), $0.06 \mathrm{M}(\mathrm{e}) ; \mathrm{pH}=0.7\left(\mathrm{a}^{\prime}\right), 1.2\left(\mathrm{~b}^{\prime}\right)$.
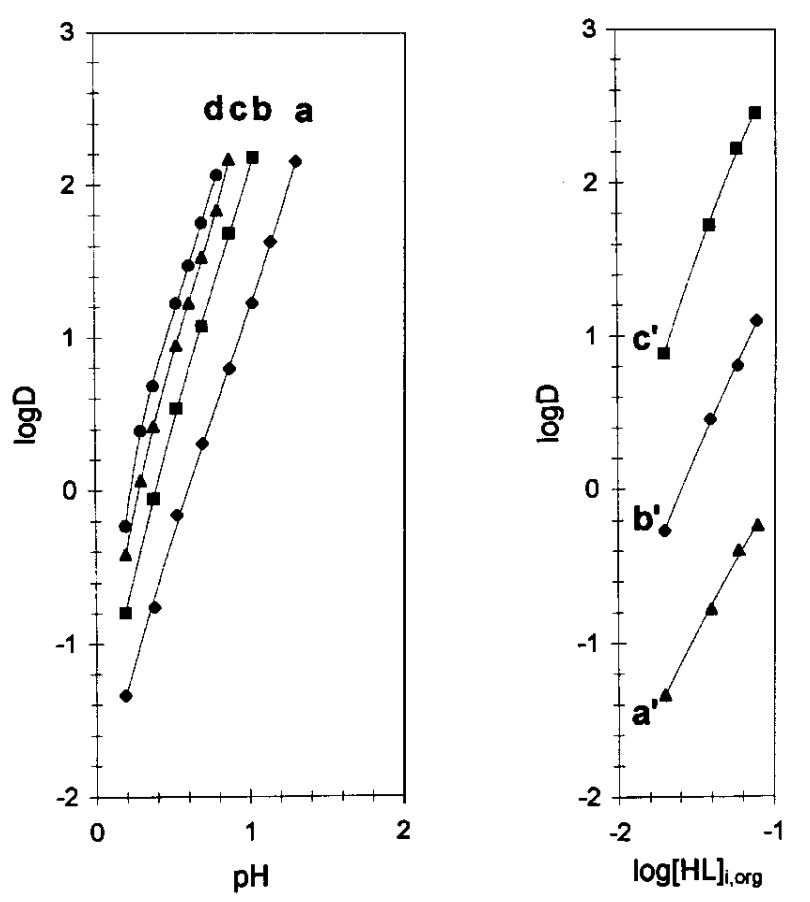

Fig. 5b. Indium(III) extraction from nitrate medium with HPBI + TOPO in toluene : influence of the cation-exchanger concentration. $(\mathrm{Na}, \mathrm{H})^{+} \mathrm{NO}_{3}{ }^{-}=1 \mathrm{M}$; $[\mathrm{In}]_{i}=2.17 \times 10^{-3} \mathrm{M} ; 25^{\circ} \mathrm{C}$; [TOPO $]_{\text {org, } i}=$ $0.02 \mathrm{M}$. [HPBI] $]_{\text {org }, i}=0.02 \mathrm{M}$ (a), $0.04 \mathrm{M}$ (b), $0.06 \mathrm{M}$ (c), $0.08 \mathrm{M}$ (d); $\mathrm{pH}=0.2\left(\mathrm{a}^{\prime}\right), 0.5$ (b'), 0.9 (c'). 
describe the extraction process. On the contrary, $K_{132}$ values do not depend on any of the above parameters, which agrees with the extraction of $\operatorname{In}(\mathrm{PBI})_{3}(\mathrm{TOPO})_{2}$ alone, within the range of experimental concentrations used:

$\log K_{132}\left(\right.$ tol, $\left.\mathrm{NO}_{3}^{-}\right)=8.95 \pm 0.06$.

Thus, the synergy equilibrium is defined as:

$\operatorname{In}(\mathrm{PBI})_{3, \text { org }}+2 \mathrm{TOPO}_{\text {org }}=\operatorname{In}(\mathrm{PBI})_{3}(\mathrm{TOPO})_{2, \text { org }}$

$\log K_{\text {syn }}=\log K_{132}-\log K_{13}$

thus $\log K_{\text {syn }}\left(\right.$ tol, $\left.\mathrm{NO}_{3}^{-}\right)=6.05 \pm 0.12$.

\section{Extraction in chloroform from nitrate medium:}

By replacing toluene with chloroform, see figure 6 , the extraction of $\mathrm{HNO}_{3}$ and the interaction between TOPO and HPBI are reduced or cancelled.

The experimental extraction curves $\log D$ vs. $\mathrm{pH}, \log D$ vs. $\log [\mathrm{HPBI}]_{\text {org, } i}$ and $\log D$ vs. [TOPO $]_{\text {org, } i}$ are approximately linear with slopes near 3,3 and 2 respectively. Thus, the nature of the extraction process is the same in both diluents. The same kind of calculations, carried out without taking into account the TOPO - HPBI interaction (equil. 2), leads

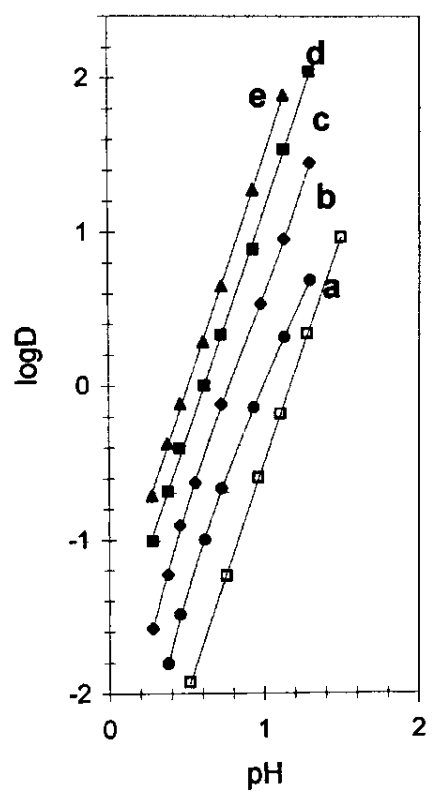

Fig. 6. Indium(III) extraction from nitrate medium with HPBI + TOPO in chloroform. $(\mathrm{Na}, \mathrm{H})^{+} \mathrm{NO}_{3}^{-}=1 \mathrm{M} ;[\mathrm{In}]_{i}=2.17 \times 10^{-3} \mathrm{M}$; $25{ }^{\circ} \mathrm{C} ;[\mathrm{HPBI}]_{\mathrm{org}, i}=0.02 \mathrm{M}$. [TOPO $]_{\mathrm{org}, i}=0.00 \mathrm{M}(\mathrm{a}), 0.01 \mathrm{M}(\mathrm{b})$, $0.02 \mathrm{M}$ (c), $0.04 \mathrm{M}(\mathrm{d}), 0.06 \mathrm{M}$ (e). to $\log K_{132}\left(\mathrm{chl}, \mathrm{NO}_{3}^{-}\right)=7.10 \pm 0.05$ and $\log K_{\text {syn }}\left(\mathrm{chl}, \mathrm{NO}_{3}^{-}\right)=$ $4.8 \pm 0.1$. As above, the extraction is more efficient in toluene than in chloroform (see Tab. VII).

It is noticeable that the synergistic effect in chloroform is lower than in toluene, in spite of the strong TOPO - HPBI interaction in the latter solvent. In the former one, however, evidence has been given of TOPO $-\mathrm{CHCl}_{3}$ interactions [18] that, due to the high concentration of the diluent, may inhibit the efficiency of TOPO as a synergist.

\section{Extraction in toluene from chloride medium:}

A very important synergistic effect is obtained with mixtures of HPBI and TOPO in toluene, e.g. $\Delta \log D \approx+4$ for $0.02 \mathrm{M}$ HPBI + 0.01 M TOPO at $\mathrm{pH} 1.4$ (extrapolated values from curves $2 b$ and $7 b$ ).

This difference is not only due to the poor extraction of indium with HPBI alone but also to an intrinsic better efficiency of the synergistic extraction from chloride medium: at $\mathrm{pH}=1.0, \log D\left(\mathrm{Cl}^{-}\right)=1.45$ compared with $\log D\left(\mathrm{NO}_{3}^{-}\right)=$ 0.66 in the above conditions (curves $7 \mathrm{~b}$ and $5 \mathrm{a}, \mathrm{b}$ ).

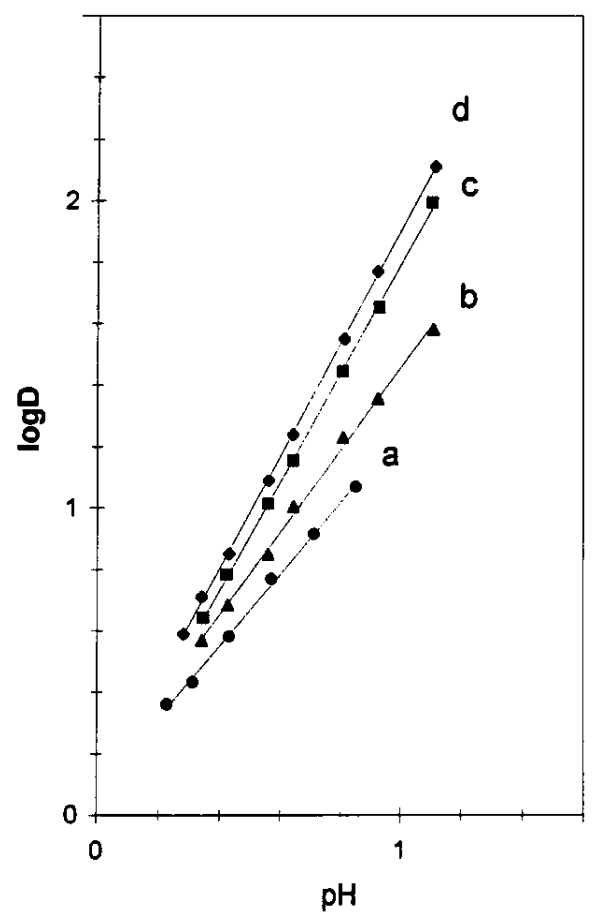

Fig. 7. Indium(III) extraction from chloride medium with HPBI + TOPO in toluene. $(\mathrm{Na}, \mathrm{H})^{+} \mathrm{Cl}^{-}=1 \mathrm{M} ;[\mathrm{In}]_{i}=2.17 \times 10^{-3} \mathrm{M} ; 25^{\circ} \mathrm{C}$; $[\mathrm{TOPO}]_{\text {org }, i}=0.01 \mathrm{M}$. $[\mathrm{HPBI}]_{\text {org }, i}=0.01 \mathrm{M}(\mathrm{a}), 0.02 \mathrm{M}(\mathrm{b}), 0.04 \mathrm{M}$ (c), $0.06 \mathrm{M}$ (d). (Note that, for clarity, the $\mathrm{pH}$ and $\log \mathrm{D}$ scales are twice that of the Figs. 2 to 6).

Table VII. Synergistic extraction of indium from $1 \mathrm{M}$ nitrate medium with HPBI + TOPO.

(1) $\mathrm{H}^{+}+\mathrm{NO}_{3}^{-}+\mathrm{TOPO}_{\text {org }}=(\text { TOPO.HX })_{\mathrm{org}}$

(2) $\mathrm{HPBI}_{\text {org }}+\mathrm{TOPO}_{\text {org }}=$ TOPO.HPBI

$(4,2) \mathrm{In}^{3+}+3 \mathrm{HPBI}_{\text {org }}+2 \mathrm{TOPO}_{\text {org }}=\mathrm{In}(\mathrm{PBI})_{3}(\mathrm{TOPO})_{2, \text { org }}+3 \mathrm{H}^{+}$

(5) $\mathrm{In}(\mathrm{PBI})_{3, \text { org }}+2 \mathrm{TOPO}_{\text {org }}=\mathrm{In}(\mathrm{PBI})_{3}(\mathrm{TOPO})_{2, \text { org }}$
$0.72 \pm 0.04$

$1.85 \pm 0.07$

$8.95 \pm 0.6$

$6.05 \pm 0.12$
$0.18 \pm 0.04$

negligible

$7.10 \pm 0.5$

$4.8 \pm 0.1$ 
With fixed concentrations of TOPO, the average slopes of the curves $\log D$ vs. $\mathrm{pH}$ vary from $1.1\left([\mathrm{HPBI}]_{\text {org }, i}=0.01 \mathrm{M}\right)$ to $1.9\left([\mathrm{HPBI}]_{\text {org }, i}=0.06 \mathrm{M}\right)$. This cannot be explained by a decrease of the free HPBI concentration by complexation upon indium or interaction with TOPO only, but rather by a complicated extraction process implying exchanges of 1 and 2 protons per In. On the contrary, the curves $\log D$ vs. $\log [\mathrm{TOPO}]_{\mathrm{org}, i}$ always show slopes $\leq 2$. Therefore, it is suggested that In is extracted as $\operatorname{InCl}_{x}(\mathrm{PBI})_{3-x}(\mathrm{TOPO})_{2}$ with $x=$ 0 to 3 , the five equilibria reported in table VIII describing the extraction process.

The extraction equilibrium of Indium with TOPO alone (8) has been previously studied under the same experimental conditions: $\log K_{8}=3.21$ [18]. The determination of $K_{6}$ and $K_{7}$ is described in the Appendix 2.

Table VIII shows that, for both acidic extractants, the extraction constants follow the order $K_{8}<K_{7}<K_{6}$ and $K_{4,2}$, with $K_{6} \approx K_{4,2}$ for HPMBP and $K_{6}>K_{4,2}$ for HPBI. Few mixed $\mathrm{Cl}^{-} / \mathrm{L}^{-}$( $\mathrm{L}^{-}$: chelatant) indium complexes have been isolated, most of them with at least a soft donor atom, e.g. $\mathrm{InCl}_{2} \mathrm{~L}(\mathrm{LH})$ with $\mathrm{HL}=$ monothiodibenzoylmethane [28], $\mathrm{InClL}_{2}$ with $\mathrm{HL}=2$-isopropylquinoline-8-thiol [29] and others $[30,31]$. It agrees with the In-O bond being stronger than the In- $\mathrm{Cl}$ one in mixed complexes, according to the general trend. Therefore, the stability of mixed $\operatorname{InCl}_{x} \mathrm{~L}_{3-x}(\mathrm{TOPO})_{2}$ complexes should decrease with $x$, as should do their lipophilicities, and hence the corresponding extraction constant. This is true from $K_{6}$ to $K_{8}$. However the relative values of $K_{4,2}$ and $K_{6}$ contradict the above expectations.
Keeping in mind that the apparent coordination numbers of indium in these complexes are uncommonly high, it is probable that in $\mathrm{InL}_{3}(\mathrm{TOPO})_{2}$, one TOPO molecule is not within the first coordination sphere of In [32,33] and may even be linked to In by $\mathrm{H}$-bonds through a water molecule, this latter being $\mathrm{H}$-bonded to a chelating oxygen atom of the PBI moiety, according to $\mathrm{R}_{3} \mathrm{PO} \bullet \bullet \bullet \mathrm{H}-\mathrm{O}-\mathrm{H} \bullet \bullet \bullet \mathrm{O}_{\text {chelate }}$-In [33]. This would decrease both the expected stability and lipophilicity of the $\mathrm{InL}_{3}(\mathrm{TOPO})_{2}$ complexes and explain the low values of $K_{4,2}$.

Since the extraction processes related to nitrate and chloride media are so complicated, the values of the extraction and interaction constants are inadequate to compare the extraction efficiencies. The choosen criterium is the $\mathrm{pH}_{1 / 2}$ corresponding to $[\mathrm{HL}]_{\mathrm{org}, i}=0.02 \mathrm{M}$, and $[\mathrm{TOPO}]_{\mathrm{org}, i}=$ $0.02 \mathrm{M}$ for synergistic extractions (see Tab. IX).

The extraction with single component HPBI or HPMBP from nitrate medium is better than from chloride medium, due to the indium complexation by the latter anion in the aqueous phase. On the contrary, in the presence of TOPO, since only $\mathrm{InL}_{3}(\mathrm{TOPO})_{2}$ is extracted from nitrate medium, while all four $\mathrm{InCl}_{x} \mathrm{~L}_{3-x}$ (TOPO) $)_{2}$ lipophilic complexes are extracted, the extraction is much more efficient in the latter case.

HPBI is always more efficient than HPMBP, sometimes not much. This is the case for the extractions from nitrate medium, the noticeable difference of extraction efficiency with single component HL extractants being almost cancelled by synergy, in part because the HPBI-TOPO

Table VIII. The extraction process of Indium from chloride medium with HPBI (or HPMBP) and TOPO in toluene.

$\begin{array}{lll}\text { EQUILIBRIA } & \log K & \log K\end{array}$

(HPBI)

$(H P M B P)$
(2) $\mathrm{HL}_{\text {org }}+\mathrm{TOPO}_{\text {org }}=$ TOPO.HL $\mathrm{Horg}_{\text {org }}$
$(4,2) \mathrm{In}^{3+}+3 \mathrm{HL}_{\text {org }}+2 \mathrm{TOPO}_{\text {org }}=\mathrm{InL}_{3}(\mathrm{TOPO})_{2, \text { org }}+3 \mathrm{H}^{+}$
(6) $\mathrm{InCl}^{2+}+2 \mathrm{HL}_{\text {org }}+2 \mathrm{TOPO}_{\text {org }}=\mathrm{InClL}_{2}(\mathrm{TOPO})_{2, \text { org }}+2 \mathrm{H}^{+}$
(7) $\mathrm{InCl}_{2}^{+}+\mathrm{HL}_{\text {org }}+2 \mathrm{TOPO}_{\text {org }}=\mathrm{InCl}_{2} \mathrm{~L}(\mathrm{TOPO})_{2, \text { org }}+\mathrm{H}^{+}$
(8) $\mathrm{InCl}_{3}+2 \mathrm{TOPO}_{\text {org }}=\mathrm{InCl}_{3}(\mathrm{TOPO})_{2, \text { org }}$

$\begin{array}{cc}1.85 \pm 0.07 & 0.85 \pm 0.07 \\ 8.95 \pm 0.06 & 7.40 \pm 0.10 \\ 9.86 \pm 0.03 & 7.37 \pm 0.10 \\ 7.50 \pm 0.06 & 5.57 \pm 0.10 \\ 3.21 \pm 0.10 & 3.21 \pm 0.10\end{array}$

Table IX. $\mathrm{pH}_{1 / 2}$ values (0.02 M HL and $0.02 \mathrm{M} \mathrm{HL}+0.02 \mathrm{M}$ TOPO).

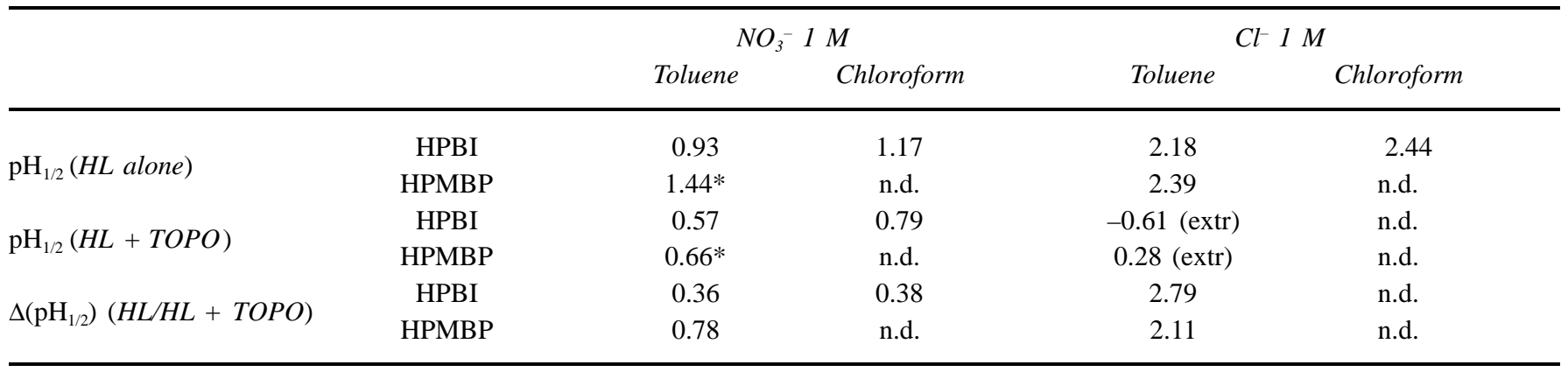

*: values estimated from measured $\mathrm{pH}_{1 / 2}\left(\mathrm{ClO}_{4}^{-}\right)$with: $\mathrm{pH}_{1 / 2}\left(\mathrm{NO}_{3}^{-}\right)=\mathrm{pH}_{1 / 2}\left(\mathrm{ClO}_{4}^{-}\right)-1 / 3 \log \alpha_{0}^{\prime}$. extr: extrapolated; n.d.: not determined. Values for HPMBP are from references [18]. 
interaction is $c a$. ten times stronger than the HPMBP-TOPO one. On the contrary, from chloride medium, the extractions with HL extractants in toluene are not much different while the TOPO-HPBI mixture is much more efficient than the TOPO-HPMBP one. This suggests that the distribution of indium between its various $\mathrm{InCl}_{x} \mathrm{~L}_{3-x}(\mathrm{TOPO})_{2}$ complexes in the organic phase is different for different $\mathrm{L}^{-}$. The result is a better synergistic effect with HPBI.

In all cases, toluene is a more efficient diluent than chloroform.

\section{Conclusion}

Indium is extracted with HPBI from nitrate or chloride media as $\operatorname{In}(\mathrm{PBI})_{3}$. Due to the rather high acidity of HPBI, this extraction takes place at low pH's: $c a .1$ and 2.3 from nitrate and chloride medium, respectively. In the last case, the complexation of In(III) with the chloride anions dramatically reduces the concentration of the extractable cation $\mathrm{In}^{3+}$ in the aqueous phase, hence a relative lowering of the extraction. The extraction efficiency in various diluents follows the order: toluene > 1,2-dichloroethane > chloroform. The factor that governs these differences is the distribution constant of the ligand.

In the presence of TOPO, the overall extraction processes are rather complicated by a number of interactions that take place in the extraction systems, even in the absence of indium: extraction of inorganic acids with TOPO, TOPO-HPBI interaction in toluene, TOPO- $\mathrm{CHCl}_{3}$ interaction. These phenomena also occur in the extraction systems with other $\beta$-keto-enols extractants of lower acidity, e.g. HPMBP, but they remain negligible: the TOPO-HPMBP interaction constant in toluene is ten times lower than the TOPO-HPBI one, the extraction $\mathrm{pH}$ range with HPMBP is 0.9 unity higher than with HPBI, which reduces the inorganic acid extraction.

Indium is extracted from nitrate medium as $\mathrm{In}(\mathrm{PBI})_{3}(\mathrm{TOPO})_{2}$. The synergistic effect due to the presence of TOPO is moderate, due in part to the above phenomena. From chloride medium, the four lipophilic $\operatorname{InCl}_{x}(\mathrm{PBI})_{3-x}(\mathrm{TOPO})_{2}$ species are extracted $(x=0$ to 3$)$. This induces an important synergistic effect, allowing for example more than $90 \%$ extraction with equimolar $0.02 \mathrm{M} \mathrm{HPBI}$ + TOPO, since $\mathrm{pH}$ 0.8. As expected, HPBI is more efficient than HPMBP in those systems, though the differences remain moderate except for the latter extraction.

\section{Appendix 1}

\section{Determination of the extraction constants of inorganic acids with TOPO}

The extraction of $\mathrm{HCl}$ and $\mathrm{HNO}_{3}$ from $(\mathrm{Na}, \mathrm{H}) \mathrm{X} 1 \mathrm{M}$ media in toluene or chloroform has been studied as follows. An organic solution containing a known amount of TOPO is equilibrated with an aqueous solution with $[(\mathrm{Na}, \mathrm{H}) \mathrm{X}]=$ $1 \mathrm{M}$ and $\mathrm{pH}=\mathrm{pH}_{i}\left(0.2 \leq \mathrm{pH}_{i} \leq 2\right)$. The equilibrium $\mathrm{pH}$ is measured $\left(\mathrm{pH}=\mathrm{pH}_{\mathrm{e}}\right)$. An aliquot of the organic phase is withdrawn and $\mathrm{HX}$ is quantitatively stripped by equilibration with a known small volume of an aqueous solution of $\mathrm{NaX} 1 \mathrm{M}$ whose $\mathrm{pH}$ is measured before $\left(\mathrm{pH}_{\mathrm{b}}\right)$ and after
$\left(\mathrm{pH}_{\mathrm{a}}\right)$ stripping. [TOPO.HX] $]_{\text {org }}$ at $\mathrm{pH}_{\mathrm{e}}$ is calculated from $\mathrm{pH}_{\mathrm{b}}$ and $\mathrm{pH}_{\mathrm{a}}$, which allows the calculation of one value of the extraction constant $K_{\mathrm{p}}$. The procedure is repeated with several values of $\mathrm{pH}_{i}$ and [TOPO $]_{\text {org, } i}$, allowing the accurate determination of $K_{\mathrm{p}}$ for the acids and diluents used below.

\section{Appendix 2}

\section{Determination of the constants $K_{6}$ and $K_{7}$}

The extraction process is described in table VIII. To explicit this process, in a first step, approximate concentrations of $\mathrm{InL}_{3}(\mathrm{TOPO})_{2}$ and $\mathrm{InCl}_{3}(\mathrm{TOPO})_{2}$ species have been calculated from the known values of $K_{4,2}$ and $K_{8}$. The TOPOHPBI interaction and the decrease of the concentrations of the free extractants by complexation have been neglected such that $[\mathrm{TOPO}]_{\text {org }}=[\mathrm{TOPO}]_{i, \text { org }}$ and that $[\mathrm{HPBI}]_{\mathrm{org}}=$ $[\mathrm{HPBI}]_{i, \text { org }}$. These calculations show that $\operatorname{In}(\mathrm{PBI})_{3}(\mathrm{TOPO})_{2}$ and $\mathrm{InCl}_{3}$ (TOPO) $)_{2}$ together contribute to less than $7 \%$ to the extraction of indium. Thus, the major extracted species are $\mathrm{InCl}(\mathrm{PBI})_{2}(\mathrm{TOPO})_{2}$ and $\mathrm{InCl}_{2}(\mathrm{PBI})(\mathrm{TOPO})_{2}$.

In a second step, since the extraction of $\mathrm{InCl}_{2}(\mathrm{PBI})$ (TOPO $)_{2}$ is favoured for low initial concentrations of HPBI, it was assumed that this species was the only extracted species for $[\mathrm{HPBI}]_{i, \text { org }}=0.01 \mathrm{M}$ and $[\mathrm{TOPO}]_{i, \text { or }}=0.01 \mathrm{M}$ (curve $6 \mathrm{a}$ ), $0.02 \mathrm{M}$ and $0.04 \mathrm{M}$ (curves not presented). Thus, $\log K_{7}$ was calculated according to this assumption for the corresponding experimental points. The average value obtained is $c a$. 7.42, but the individual values vary with the extraction parameters. In the same manner, $\log K_{6}$ was calculated for every point of the curve (6d), assuming that only (6) and (2) describe the extraction process. A comparable result was obtained, with $\log K_{6} c a$. 10.1 .

Finally, to ascertained these results, a precise method which takes into account the interaction of the extractants and the extraction of both $\mathrm{InCl}(\mathrm{PBI})_{2}(\mathrm{TOPO})_{2}$ and $\mathrm{InCl}_{2}(\mathrm{PBI})(\mathrm{TOPO})_{2}$ has been developed.

The equilibria taken into account for this calculation are:

$$
\begin{aligned}
& \mathrm{HPBI}_{\text {org }}+\mathrm{TOPO}_{\text {org }}=\text { TOPO.HPBI }{ }_{\text {org }}\left(\mathrm{Csnt}: K_{\text {int }}\right) \\
& \mathrm{InCl}^{2+}+2 \mathrm{HPBI}_{\text {org }}+2 \mathrm{TOPO}_{\text {org }}=\mathrm{InCl}(\mathrm{PBI})_{2}(\mathrm{TOPO})_{2, \text { org }}+2 \mathrm{H}^{+} \\
& \text {Let HPBI }=\mathrm{HL} ; \mathrm{TOPO}=\mathrm{S} ;[\mathrm{In}]_{\mathrm{org}, 1}=\left[\operatorname{InClL}_{2} \mathrm{~S}_{2}\right]_{\mathrm{org}} \text {; } \\
& {[\mathrm{In}]_{\mathrm{org}, 2}=\left[\mathrm{InCl}_{2} \mathrm{LS}_{2}\right]_{\text {org }} \text {. }}
\end{aligned}
$$

Given an experimental point, the following relations stand:

$$
\begin{aligned}
\log K_{6}= & \log [\mathrm{In}]_{\mathrm{org}, 1}-2 \mathrm{pH}-\log \alpha_{1}-\log [\mathrm{In}]_{\mathrm{t}} \\
& -2 \log [\mathrm{HL}]_{\mathrm{org}}-2 \log [\mathrm{S}]_{\mathrm{org}} \\
\log K_{7}= & \log [\operatorname{In}]_{\mathrm{org}, 2}-\mathrm{pH}-\log \alpha_{2}-\log [\mathrm{In}]_{\mathrm{t}}-\log [\mathrm{HL}]_{\mathrm{org}} \\
& -2 \log [\mathrm{S}]_{\mathrm{org}} \\
{[\mathrm{In}]_{\mathrm{org}}=} & {[\operatorname{In}]_{\mathrm{org}, 1}+[\mathrm{In}]_{\mathrm{org}, 2} } \\
{[\mathrm{~S}]_{\mathrm{org}}=} & {[\mathrm{S}]_{\mathrm{org}, i}-2[\mathrm{In}]_{\mathrm{org}}-[\mathrm{HL} \cdot \mathrm{S}]_{\mathrm{org}} }
\end{aligned}
$$




$$
\begin{aligned}
& {[\mathrm{HL}]_{\mathrm{org}}=[\mathrm{HL}]_{\mathrm{org}, i}-2[\mathrm{In}]_{\mathrm{org}, 1}-[\mathrm{In}]_{\mathrm{org}, 2}-[\mathrm{HL} . \mathrm{S}]_{\mathrm{org}}} \\
& K_{\text {int }}[\mathrm{HL}]_{\mathrm{org}}[\mathrm{S}]_{\mathrm{org}}=[\mathrm{HL} . \mathrm{S}]_{\mathrm{org}}
\end{aligned}
$$

It would be very uneasy to solve the problem by mathematics only. However, the actual concentration of $\mathrm{HL}_{\text {org }}$ can vary only between $[\mathrm{HL}]_{\mathrm{org}, i}-2[\mathrm{In}]_{\mathrm{org}}-[\mathrm{HL} . \mathrm{S}]_{\mathrm{org}}$ (which corresponds to the extraction of $\mathrm{InClL}_{2} \mathrm{~S}_{2}$ only) and $[\mathrm{HL}]_{\text {org }, i}$ $-[\mathrm{In}]_{\text {org }}-[\mathrm{HL} . \mathrm{S}]$ (if $\mathrm{InClL}_{2} \mathrm{~S}_{2}$ only is extracted). The related values $[\mathrm{HL}]_{\text {org, } \min }$ and $[\mathrm{HL}]_{\text {org, } \max }$ are easily calculated: $[\mathrm{HL}]_{\mathrm{org}, \max }=[\mathrm{HL}]_{\mathrm{org}, i}-[\mathrm{In}]_{\mathrm{org}}$ and $[\mathrm{HL}]_{\mathrm{org}, \min }=[\mathrm{HL}]_{\mathrm{org}, i}-2$ $[\mathrm{In}]_{\mathrm{org}}-[\mathrm{HL} . \mathrm{S}]_{\mathrm{org}, i}$. [HL.S $]_{\mathrm{org}, i}$, which is the highest possible concentration of (HL.S) is calculated from $f$, with $[\mathrm{HL}]_{\text {org }}=$ $[\mathrm{HL}]_{\mathrm{org}, i}$ and $[\mathrm{S}]_{\mathrm{org}}=[\mathrm{S}]_{\mathrm{org}, i}$. Then, discrete, decreasing values were attributed to $[\mathrm{HL}]_{\text {org }}$, from $[\mathrm{HL}]_{\text {org, max }}$. The corresponding values of $\log K_{6}$ and $\log K_{7}$ were determined as follows:

Given $[H L]_{\text {org }},[S]_{\text {org }}$ and [HL.S $]_{\text {org }}$ are easily calculated using $d$ and $f:[S]_{\text {org }}$ is the solution of a quadratic equa -

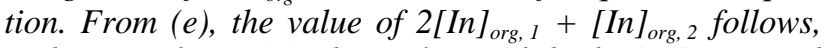
and next, from (c) the values of both [In] $]_{\text {org, } 1}$ and $[\mathrm{In}]_{\text {org, } 2}$ are obtained. Thence, a pair of values $\left(\log K_{l}\right.$, $\left.\log K_{2}\right)$, corresponding to the given $[H L]_{\text {org }}$ value, is cal culated from $(a)$ and $(b)$.

The procedure was repeated for the next value of $[\mathrm{HL}]_{\text {org }}$ and so on. The result, which corresponds to one experimental point, was a list of pairs of $\left(\log K_{6}, \log K_{7}\right)$ values that may be represented as a curve in a plane with $\log K_{6}$ and $\log K_{7}$ as ordinates (Fig. 8). Inevitably, this curve contains the unique point corresponding to the true values of the constants. Such a curve was drawn for each experimental point.

All these curves cross in one and the same point which corresponds to the true values: $\log K_{6}=9.86 \pm 0.03 ; \log K_{7}=$ $7.50 \pm 0.06$.

The values obtained show that the previous rough approximations gave a rather good idea of the quantitativity of the process, nevertheless.

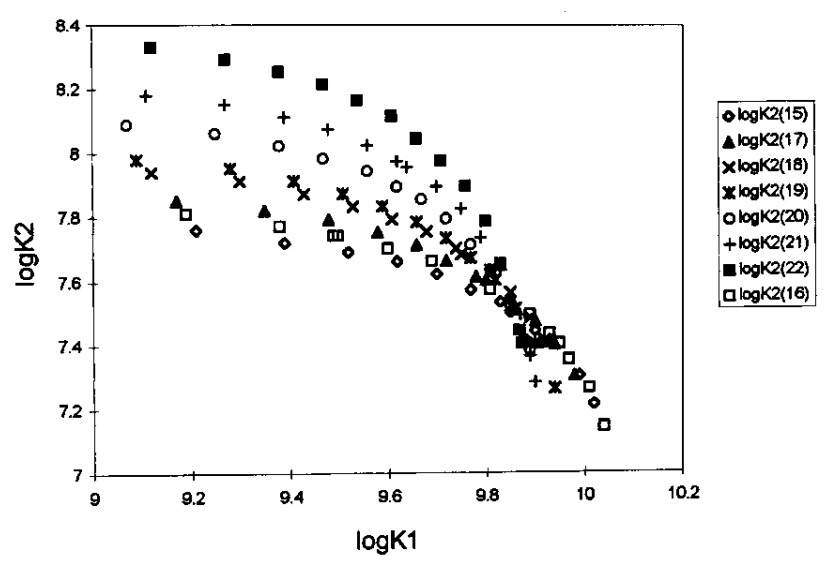

Fig. 8. Determination of $\log K_{6}$ and $\log K_{7}$. Each curve corresponds to one experimental point (named 15 to 22). In every case, the value of $[\mathrm{HPBI}]_{\text {org }}$ taken into account in the calculation increases from left to right.

\section{References}

1. Jyothi, A.; Rao, G. N. Chem. Scripta 1987, 27, 367.

2. Torkestani, K.; Blinova, O.; Arichi, J.; Goetz-Grandmont, G. J.; Brunette, J. P. Solvent Extr. Ion Exch. 1996, 14(6), 1067.

3. Messaoudi, A.; Torkestani, K.; Goetz-Grandmont, G. J.; Brunette, J. P. J. Radioanal. Nucl. Chem., Art. 1996, 208(1), 123.

4a. Umetani, S.; Hanh Le, Q. T.; Takahara, T.; Matsui, M. Proc. Int. Solvent Extr. Conf., "ISEC'93”, Elsevier, Amsterdam, 1993; p 643.

4b. Matsui, M.; Bunseki Kagaku 1996, 45, 209.

5. Kuroda, Y.; Ito, H.; Matumura, S.; Odashima, T.; Ishii, H. Proc. Symp. Solvent Extr., 1994; pp 47-8.

6a. Reddy, M. L. P.; Varma, R. L.; Ramamohan, T. R.; Rao, T. P.; Iyer, C. S. P.; Damodaran, A. D.; Mathur, J. N.; Murali, M. S.; Iyer, R. H. Radiochim. Acta 1995, 69(1), 55.

6b. Reddy, M. L. P.; Varma, R. L.; Ramamohan, T. R.; Damodaran, A. D.; Thakur, P.; Chakravortty, V.; Dash, K. C. Solvent Extr. Ion Exch. 1997, 15, 49.

7. Mansingh, P. S.; Veeraraghavan, R.; Mohapatra, P. K.; Manchanda, V. K. Radiochimica Acta 1996, 72(3), 127.

8. Manchanda, V. K.; Mohapatra, P. K.; Veeraraghavan, R. Anal. Chim. Acta 1996, 320, 151.

9. Thakur, P.; Veeraraghavan, R.; Mohapatra, P. K.; Manchanda, V. K.; Dash, C. K. Talanta 1996, 43(8), 1305.

10. Hanh Le, Q. T.; Umetani, S.; Takahara, H.; Matsui, M. Anal. Chim. Acta 1993, 272, 293.

11. Umetani, S.; Matsui, M. Bull. Chem. Soc. Jpn. 1983, 56, 3426.

12. Jyothi, A.; Rao, G. N. Spectrochim. Acta 1987, 43A, 517.

13. Jyothi, A.; Rao, G. N. Spectrochim. Acta 1987, 43A, 961.

14. Jyothi, A.; Rao, G. N. Synth. React. Inorg. Met.-Org.Chem. 1988, 18, 487.

15. Goetz-Grandmont, G. J.; Chaoui Roqai, M.; Brunette, J. P.; Kaufmann, G. Solvent Extr. Ion Exch. 1996, 14(4), 653.

16. Ishii, H.; Satoh, S.; Odashima, T. Solvent Extr. Ion Exch. 1993, 11,423 .

17. Brunette, J. P.; Taheri, M.; Goetz-Grandmont, G. J.; Leroy, M. J. F. Polyhedron 1982, 1(5), 457.

18. Brunette J. P., Taheri M., Goetz-Grandmont G. J., Leroy M. J. F. Solvent Extr. Ion Exch. 1985, 3(3), 309.

19. Jensen, B. S. Acta Chem. Scand. 1959, 13, 1668.

20. Ferri, D. Acta Chem. Scand. 1972, 26, 733.

21. Aguilar, M.; De Pablo, J.; Valiente, M.; Högfedt, E. Chem. Scripta 1986, 26, 635.

22. Ferguson, R. C.; Dobud, P.; Tuck, D. G. J. Chem. Soc. (A) 1968, 1058.

23. Torkestani, K.;. Goetz-Grandmont, G. J.; Brunette, J. P. Solv. Extr. Ion Exch. 1997, 15, 819.

24. Messaoudi, A.; Thèse de l'Université Louis Pasteur, Strasbourg (France), 1988.

25. Niitsu, M.; Sekine, T. J. Inorg. Nucl. Chem. 1975, 37, 1054.

26. Stary, J.; Freiser, H.; "Equilibrium Constants of Liquid-Liquid Distribution Reactions: Part IV, Chelating Extractants", IUPAC additional publication, 1978, Pergamon Press, Oxford.

27. Sekine, T.; Hasegawa, Y.; "Solvent Extraction Chemistry: fun damentals and applications", Marcel Dekker, New York 1977, p 158.

28. Mishra, A. K.; Gupta, V. D. Z. Naturforsch . 1986, 41b, 1219.

29. Cheklov, A. N. J. Struct. Chem. 1994, 35(5), 727.

30. Abram, S.; Maichle-Mössner, C.; Abram, U. Polyhedron 1997, 16(13), 2183.

31. Abram, S.; Maichle-Mössner, C.; Abram, U. Polyhedron 1997, 16(13), 2291.

32. Goetz-Grandmont, G. J.; Taheri, M.; Brunette, J. P. Solv. Extr. Ion Exch. 1992, 10, 243.

33a. Gao, J.; Fan, H.; Peng, B.; Kang, J. Rare Met. (Beijing) 1997, 16, 20 (Chem. Abstr., 126: 335042t)

33b. Kusakabe, S. Solv. Extr. Ion Exch. 1997, 15, 219. 